\title{
Appraisal of Mass Media in Reporting Domestic Research Results: Ethiopian News Agency (ENA) and Walta Information Center (WIC) in Focus
}

\section{Asmamaw Addis Amera, Dilla University, Ethiopia}

\begin{abstract}
The aim of this research is to analyze news coverage of two wire services in Ethiopia, namely ENA and WIC. The research also appraises the role of these news media in relation to the contribution of local research dissemination. 340 sample news stories are chosen for content analysis from both wire services. Systematic sampling technique is employed to pick representative news items. The selected stories have been covered by news media of the country. 18 key informants are also used purposively for interview. The findings of the study have shown that the range of ENA and WIC news coverage is diverse and wide, but the proportion given to issues in news coverage is imbalanced. Educational, health, agricultural and science and technology, for example, are local topics that have got very little news recognition and attention. The coverage of local and foreign research findings of ENA is almost the same and equal in proportion. Whereas in the case of WIC, the coverage of foreign research findings is quadruple than the coverage of local research findings. This indicates local research findings have got little attention and recognition in the news coverage. It shows journalists' engagement in reporting and popularizing local research findings is very low. Even, the finding from the news media further implied that the researchers are less attracted by the media.
\end{abstract}

Keywords: news coverage, local research dissemination, ENA, WIC 


\section{Introduction}

Ethiopia is an important country in many ways. A large country of 1.1 million $\mathrm{km} 2$, it is strategically positioned in the troubled Horn of Africa. With a population of nearly 95 million people, Ethiopia is the second most populous country in sub-Saharan Africa. Economic growth rates have been high in recent years, averaging nearly 8\% between 2013 and 2014. Yet almost $10 \%$ of the population experiences chronic food insecurity, and although poverty levels are slowly declining, around 36\% of Ethiopia's people live below the $\$ 1$ a day poverty line. Despite signs of progress, the development challenge remains both massive and urgent. With regarding to the reduction of poverty level, the contribution of media is central. That is why international community, with confidence, acknowledged the role of media for sustainable development (UNESCO, 2014). The recognition of the role of media for sustainable development is due to its importance for public participation and the interaction of state and non-state actors.

News media, especially in developing countries like Ethiopia, are expected to publicize matters that would contribute for the development of the society. Among these matters, research results which have been found by researchers in different higher institutions, research centers and/or at individual and organizational levels, would play a great role in solving their societal problems.And, their inputs deserve special consideration in the policy making process. Hence, the highest degree of media coverage enforce policy makers to pay attention for issue and realize implementation of the research results. Research results can also help to make informed decisions on important public issues if they are easily accessible to the stakeholders. On the other hand, journalists have responsibility to inform the society whether researches are being done well or not, since many researchers carry out studies with public fund. Here, it is important to keep in mind the watchdog function of the media must motivate journalists to communicate research.

A researcher of this study also believed that media coverage of research often results invaluable contacts with potential collaborators and the general public. As Nordfors (2004) explains news items are important to disseminate information because "most people repeat what is said in the news, so the journalists' level of understanding about the reported matters often be fundamental importance for the level of insight in the public debate and the quality of the shared common knowledge." (p.4) 
In Ethiopia, the most sources of news information and distribution for the people and the news media (radio, TV, newspapers, internet, etc.) are wire services. A report, for example, estimated that $90 \%$ of Ethiopian Radio's news items came from Ethiopian News Agency (ENA) and Walta Information Centre (WIC) (Stanbridge \& Ljunggren, as cited in Skjerdal, 2012). These two wire services are established, the study area of this research, as a news agency and as an information center respectively. And both of them are involved in covering and supplying news items to other news media. ENA was established in 1942, as a government news service under the Ministry of Pen. Its function is to gather and distribute balanced and accurate news and news materials concerning Ethiopia and the rest part of the world. It has been engaged in the gathering, writing and editing of news in all of Ethiopia's regions through 37 branch offices. It oversees news coverage of development in all the regional states. It has also the foreign languages desk. The other news agency WIC was established in 1994 as private wire service and focuses on the development related news and information coverage throughout the regional states. It has over 34 different stations all over Ethiopia that send information on a daily basis (Sweden International Development Association [SIDA], 2003).

There are a number of works on how journalists disseminate research in Africa and other countries (Akala, 2004; Nordfors, 2004; Thelwall, 2002). However, many of the study did not consider wire services as their study part and particularly news as alternative form of disseminating research findings. And again, to the extent of the researcher's knowledge there is no similar research conducted in Ethiopian news media whether they cover local research findings. Therefore, it is worth to study wire services' standing in reporting local research findings as news form.

\section{Objectives}

The objective of this study delves into the role of ENA and WIC in disseminating the topic of local research findings, and whether these have been covered in news media or not. Specifically, the following objectives are considered:

- To study to what extent the two wire services are engaged in disseminating topics of local research findings.

- To show the significance of the two wire services in popularizing topics of local research findings in their news coverage for general public and policy makers. 
- To identify potential challenges of journalists in the wire services to report topics of local research findings.

\section{Research Questions}

Do wire services' editorial policies /the news media policies/ allow journalists to treat topics of local research findings as the news? How wide the wire services/news media coverage of topics of local research findings in their news stories? What are the challenges that reporters encounter in reporting local research findings? What types of local research findings are prioritized in their news selection process? These are the basic questions that the researcher attempts to answer and examine in the study.

\section{Statement of the Problem}

Science information, frequently domestic research findings are being inadequately addressed in the mass media. It is apparent this observable fact becomes common across the world. "Most research projects, of several million concluded each year in the world, are never addressed in the media, and rightly so because they all but lack public interest. And it is the media, not the scientists, which decide what is of interest to the public" (Bauer \& Bucchi, 2007, p. 126). On the other hand, currently journalism itself has become the subject of study due to two major reasons, i.e. "the fragmentation of audiences and the trivialization of the contents" (Schudson, 2003, p.12).

It is, however, believed that amongst journalists' mission "in many countries the basic one is to serve the citizens by informing them about recent developments ('news') and by naming and warning of insufficiencies of various kinds" (Bauer \& Bucchi, 2007, p. 126). In this regard, most certainly, science information, including research outcomes, can be useful to report the aforementioned activity for the society.Furthermore, the task of journalism is to disseminate knowledge that is beneficial to human well-being and democratic process and to make a cultural contribution by selecting and processing information. Then, processing and disseminating local research topics in their news coverage is indisputable. As Fjastand explains, however, "many scientists claim that the media do not fully appreciate the inherent importance and interest of science... that journalists often have little scientific education and that, in the end, they tend to obstruct rather than to facilitate communication between scientists and the public" (Ibid, p.123). 
As European Commission also reported:

The media are key shapers of public opinion. More effective communication to the public is increasingly necessary for the scientific community, but without media support this goal remains out of sight. Meanwhile, Europe's current performance in disseminating its research results through mass media often fails to match the excellence of its research. The multitude of opportunities for scientists to act as the interpreters of everyday occurrences is not taken up by the media and subsequently the chance to help people to really understand the world that they live in is lost. (2007, p. 3)

Studies show that the role of news media in disseminating topics on local research findings and watching over researchers in our country are limited. Besides, commissioning structures are also limited in embedding of local researches in the society. Mainly, researchers in Ethiopia, after conducting their research, are only looking to publish their investigation on journals (usually at international level) and presenting for their own colleagues rather than to the public by using news media. This may restrict to publicize results only for other researchers who do have an access and a capacity to afford these journals and presentations.

There is, however, increasing recognition of the need for intermediary organizations that can bring a communication perspective and expertise and support effective communication of research results (Vincent, 2005, p. 4). Free media coverage can be an easy way to get results out to as many people as possible. Therefore, the researcher believes assessing the role of wire services/ news media in disseminating local research results would have a paramount importance to this regard. Therefore, in this study, the goal is to assess the news of the wire services whether contents are embraced topics on research findings which, in turn, are imperative particularly for the progress of the country. Thus, it is believed that the study is helpful for the worthiness of their stories and to improve their communicative value, and in general what would be the constituents of news in the contemporary practicing of journalism.

\section{Scope of the Study}

The main focus of the study is limited on the role of news media in disseminating and covering local research results, particularly coverage of applied research results. This is due to researcher's 
conceptions. That is applied research results must be covered through media as they are primarily carried out to solve the immediate problem of the society. Besides, there is an argument on basic research that it might not worth for media reporting; all of them are done with assumption that they will be consumed by scholars and aimed at primarily for theoretical development.

Moreover, ENA and WIC are chosen because they are the only local providers of news to all the mainstreaming media of the country. The research will then include only Amharic news coverage of ENA and WIC due to two reasons. One, it is more convenient for the researcher to study one language and one format of journalistic presentation rather looking all journalistic forms of presentations, and secondly, the concern of the research is analyzing local research findings for the consumption of the country development.

\section{Application of Results}

The study results will be used by media practitioners in any media of the country; such as, newspapers, radio, $\mathrm{TV}$, online, including wire services to improve their work corresponding to research findings. Domestic research findings will be enclosed as issues of the news and will be reached to the public so that they serve as key in for their country development as well as problemsolving practice. It may be used by communication policy makers to design policies that best fits in disseminating research findings, and policy makers will consider communicating researches to the public shall be a responsibility of both (researchers and journalists) professionals. The results can be used by other researchers and media practitioners to accomplish further research in the area of the study.

\section{Limitation of the Study}

The study is inhibited that it is not included the perspective of researchers, managers of research centers and scholars in the universities. Moreover, it is not included broadcasters and publishers of mass media other than the wire services. Even though the stories that are produced at the national level are included since they are simply available at their database, the responses of journalists who are working at branch offices of ENA and WIC are excluded in the sampling frame. These are due to the fact that budget and time constraints. 


\section{Literature Review}

\section{Science and Media}

There has been a growing interest in the relations between science and the media to reach the public since the 1980s. These relationship has begun because of the inadequate of scientific literacy of the public or distorted public image of science (Valiverronen, 1993). However, their relationship throughout time is incoherent and incomplete. He (1993) mentioned three useful perspectives on relationship between science and media; such as,

- Science and scientists as a topic and object in the media,

- Scientific institutions and scientists as actors towards the media, and

- $\quad$ Scientists and professionals as expert-sources in the media. (p.28)

Even though the three perspectives have important implications to understand the interaction between them, interaction between the scientific world and that of the news media is inevitable and, overall, positive, but it is also quite complicated (Semir, 2000, p. 125). The communication of scientific knowledge to the general public via mass media requires a new relationship between the world of science and that of the news media, and this relationship is still just beginning to be explored. On the other hand, the relationship between science and public has been determined by the public interest in science and their scientific literacy level. For example, Miller's survey (2001) indicated that the public in USA have high levels of interest in science but continuing low level of accessible understanding of science (as cited in Burns, O'conner \& Stocklmayer, 2003, p.186). From this point of view, one can understand media must play an intermediary role in creating accessibility of science and research results to the public. This is why the researcher is motivated to appraise the role of Ethiopian news media whether they are covering the research findings or not.

\section{Science Journalism}

Patairiya (2007) said that science journalism is the key to the real treasure of the scientific knowledge, by virtue of which scientific knowledge and concepts could be carried to the common man. Science journalism has been viewed as a special discipline in the field of science communication or a genre in the discipline of journalism, which has a special attention to media coverage of science. It is an additional role of watchdog and critic that media at their best to fulfill (Brumfiel, 2009, p.275). The goal of science journalism is to create an informed public who are: 
"aware of the social, political and economic implications of scientific activities, the nature of evidence underlying decisions, and the limits as well as the power of science as applied to human affairs" (Metcalfe \& Gascoigne, 1995, p. 411-412). Thus the common man is benefited with the new advancements in science and technology and is able to fight against hunger, drought, diseases, and social evils with self-confidence, courage and faith. Simultaneously, access to knowledge is essential in the development process (Chan \& Costa, 2005).

During early days, however, there was no science communication or journalism, as such. Scientific communication was studied extensively in the 1960s (Lievrouw, 1990). And science journalism boomed in the 1980s and early 1990s in USA and Europe. Science journalism in Africa has yet to come out of its present stage of infancy. Equally in Ethiopia, it is very difficult to pin point a single incident being origin of science communication/journalism in the country. However, there was a "sphere of interaction between the techno-science and the public in Ethiopia in the second half of the 1960s." Tenaw (2006) stated as there were some individual efforts in popularizing science and technology to the public. From Tenaw's work, the researcher understands that attention has given in the public policy for science and technology with varied degree of emphasis in different regimes. Research findings and innovation of technology can be also viewed as agents of modernization. Even if they are viewed as agents of modernization, weaknesses and strengthens of Ethiopian media in disseminating and addressing these agents to the larger public is not yet investigated. Moreover, recently globally mass media have frequently failed to practice science journalism properly or to cover science; i.e., due to two pressures: commercialization and segmentation of audience (Schudson, 2003).

\section{Theories of Science Communication}

\section{Deficit Model}

This model viewed the public as having inadequate knowledge, and science as having all the required knowledge (Burns, O’Connor, \& Stocklmayer, 2003). The model is asymmetrical. It depicts communication as a one-way flow from science to its publics, which limits the potential for social applications of science. This was held to be responsible for the supposed negative attitudes to science. The response to this deficit was to encourage the provision of scientific information to the public, in forms usually designed to appreciate science. However, people who learn more about a 
scientific issue or technique do not necessarily feel more positive towards it as a result of that learning (Bauer \& Bucchi, 2007). From the above statements, someone can understand the role of the news media is transmitting scientific information to the general public. Therefore, the model sees journalists as information translators and interpreters.

\section{Contextual Approach}

This model depicts communication as a two-way flow between science and its publics. It assumes that scientific issues that arose in local circumstances could be discussed between experts and laypeople. This contextual approach acquired the label 'dialogue' or 'interactive' model. It is a symmetrical approach. Hence, the contextual model implies that there is an active public and sufficient public space (for example mass media). It requires of institutions and their publics that they co-construct a discussion on topics of mutual interest, and that the results of this discussion contribute to the shaping of science and science policy (Bauer \& Bucchi, 2007). Thus, it requires "rhetoric of reconstruction in which public understanding is the joint creation of scientific and local knowledge" (Burns, O’Connor, \& Stocklmayer, 2003, p. 190).

\section{Other Media Theories}

It is known that the operation of news process has two basic features of news production that are gate-keeping and agenda-setting. Thus, the researcher deals with as theoretical frames of the study. And these will help him to determine some factors that affect the coverage of local research findings in Ethiopian media.

\section{Gate-Keeping Theory}

As Watson (2003) gatekeeping is defined as "about opening or closing the channels of communication; it's about accessing or refusing access." (p. 123) There could be a number of competing news items, among different beats of the story and science stories developed from research results, not only among stories, but also within science stories. Therefore, at different gates of the news organization, there would be selection of these items that are considered to be sufficient interest and importance to the public. At every stage in the news process, "decisions are taken, not only about events to cover, but how these might be covered and by whom" (Watson, 2003, p. 124). 
Decision - makers, they can be reporters, sub-editors and editors, have many more messages to send than they can accommodate. So they decide which messages get through.

\section{Agenda Setting Theory}

McCombs and Shaw stated one function of mass media is "the ability to transfer the salience of items on their news agendas to the public agenda" (Griffin, 2000, p. 360). In other words, it clearly establishes "there is an important relationship between media reports and people's ranking of public issues" (Baran \& Davis, 2012, p. 295). That is called agenda setting. The word agenda can be defined as "a list of items, usually in descending order of importance" (Watson, 2003, p. 127). Here it is also important to understand that "overt agenda is synonymous with public agenda; i.e., what is most important to the public appears to top of the media agenda" (Ibid, p. 128). It has two basic features, one, it reaffirmed the power of media to influence the public perception, and second, individuals also can maintain their freedom to choose what they want and need from the media. In this sense, the researcher can understand that mass media become more effective in establishing the importance of some topics.

Griffin (2000) also supported that some issues are more dependent on the media coverage to raise public consciousness and conscience. For example, Bosso found that news organizations were slow to react to famine in Ethiopia in the 1980s whereas when they picked the story the coverage got great public concern (as cited in Griffin, 2000, p. 365). From this theoretical perspective, the researcher will frame how far the news media treat local research findings as important constitute of the news.

\section{Methodological Approach}

The research methodology is a mixed-approach. Mixed - approach can be conceived of a source of either meaning, in phenomenological term, or information, in the sense of discrete items transporting significance through mass media (Jensen \& Jankowski, 2002). Mixed - approach also enables him to keep the accuracy of the data. Therefore, the methodology enables the researcher to better understand how news organizations transform local research findings into news, or how they define facts for dissemination, and to examine how far they are giving them coverage. 


\section{Data Collection Tools and Sampling Techniques}

\section{Content Analysis}

Content analysis is used to collect and analyze quantitative data. The researcher uses content analysis to identify whether local research findings are constituents of the news or not, or to see the accurate representation of local research findings as ingredients of news in the local media. Use of content analysis makes the researcher advantageous because of the following benefits (Wimmer and Dominick, 2000):

- describing patterns or trends in media portrayals, or to identify what exists;

- testing hypotheses of message characteristics;

- comparing media content with the real world;

- assessing the representation of particular groups in society; and

- drawing inferences about media effects.

Therefore, in the study, frequency and characteristics of the story coverage are analyzed as quantitative content factors. "As we make certain the frequency with which certain social behaviors or groups appear in the media coverage, we can get important information about the motives or agenda of media producers" (Gutner, 2000, p. 57).

\section{Interview}

Interview is also employed to analyze qualitative contents of the news coverage for reporters and editors in both offices. Gans (1979) also complemented interviews with quantitative content analysis in order to reveal some general characteristics of news reporting (Jensen \& Jankowski, 2002). The primary strength of interviewing as a method is, however, its capacity to range over multiple perspectives on a given topic. Another pleasure of interviewing is to discover how analytically aware practitioners are (Jensen \& Jankowski, 2002, p. 101). Moreover, the researcher uses for triangulation and generalization of the results.

\section{Units of Analysis}

The researcher purposively selects the time interval from March 10, 2014 to June 10, 2014 to identify the population of the subjects from WIC and ENA since the researcher can't manage if all stories are involved. And these are enabled the researcher to draw data that can show the recent 
development of news media in relation with coverage of the research findings. Moreover, news stories that have been covered at least in one media of the country (it can be radio, TV, newspaper, magazine or internet), counts as population of the study. The news that has got media coverage is known since both of the wire services have tallied soon any of the news media aired or published, including publishing on their websites (personal interview, 2013). Systematic random sampling technique is employed to choose representative news items of the subjects. From the selected time interval, all the sixth items of the news stories are included. Totally, 340 sample news stories are chosen from both wire services. 244 news stories are from ENA, and 96 news stories are from WIC. 18 key informants are used purposively in in-depth -interview. 4 of them are media mangers the remains are news editors (6) and senior reporters (8) from the two offices. This is done because experience and knowledge of the journalists are weighty to grip the response of media towards to coverage of local researchers and their work.

\section{Content Analysis Protocol}

All of the selected news stories in both wire services are classified, counted and categorized into nine major themes; such as, political affairs, health issues, business issues, art and entertainment affairs, social issues, agriculture issues, education, science and technology and foreign policy. Among selected ones in the sampling frame, news stories that are focused on research findings are selected and counted, based on research identification; such as, empirical data presented, statistical inferences presented, data quoted from research reports and research methods used in the news stories. These selection and categorization criteria are adapted and modified from Akala (2004) to distinguish which of the stories are born out of the research.

These stories are further classified and counted based on sources of information; such as, news stories developed from source -originated materials (speeches, press releases, meetings, research reports, journals, seminars, and news conferences), reporters' observation, and foreign news sources. Then news stories, which are born out of research, are taken to detail analysis. Each news stories that basis of research findings is coded in terms of formal characteristics (e.g., size, presence of name of the researcher/s and narrative elements that are representation of actors, andgeographic context of the story). A few of the above content protocols (particularly, formal characteristics and 
narrative elements) are used by adapting and modifying the Bucchi and Mazzolini's protocols that were used to examine science coverage in the Italian daily press (Bauer \& Bucchi, 2007).

\section{Data Analysis}

The researcher has worked data coding jointly with two graduate assistants of Journalism and Communication department at Dilla University in the identified news stories into different categories based on the coding sheets, just to ensure coders reliability. Reliability in content analysis is defined as agreement among coders about categorizing content. The two graduate assistants have been trained to apply the coding protocol that had been defined by the researcher. The results of the study are presented in percentages and charts with which the values of a variable occurred. The content analysis coding scheme provides the basic guidance for such a display. Interpretative arguments also supported the presentation. The research data are analyzed thematically. The themes are driven form the data itself.

\section{Results and Discussion}

\section{General Features of News Coverage}

Analysis of the percentage of topics of the news, which is the degree of their frequency of appearance in any of local media, has taken the topics that have got media attention. As it shown in the chart (see Figure 1), ENA has given greater attention for issues of politics (17.25\%), social issues (16.39\%), and international issues (18.44 \%) than others issues. Likely, WIC has said very much about business issues (20.83\%) in its news coverage than others. On the contrary, both wire services have given a little news attention for educational issues (ENA, 3.69\%; WIC, 7.29\%) and science and technology (ENA, 2.46\%; WIC, 5.21\%). The degree of news coverage given for the topics of art and entertainment, social affairs, educational and science and technology has no significantly differ between the two organizations. On the other hand, the two news media have equally concerned on the topics of health $(7.38 \%)$ and foreign policy and diplomacy $(12.5 \%)$ in their news coverage. From the chart, it is also revealed that there is a significant difference between the two media in covering politics (ENA, 17.21\%; WIC, 10.42\%), business (ENA, 6.97\%; WIC, 20.83\%), agriculture (ENA, 5.74\%; WIC, 11.46\%) and international issues (ENA, 18.44\%; WIC, 4.17\%). 


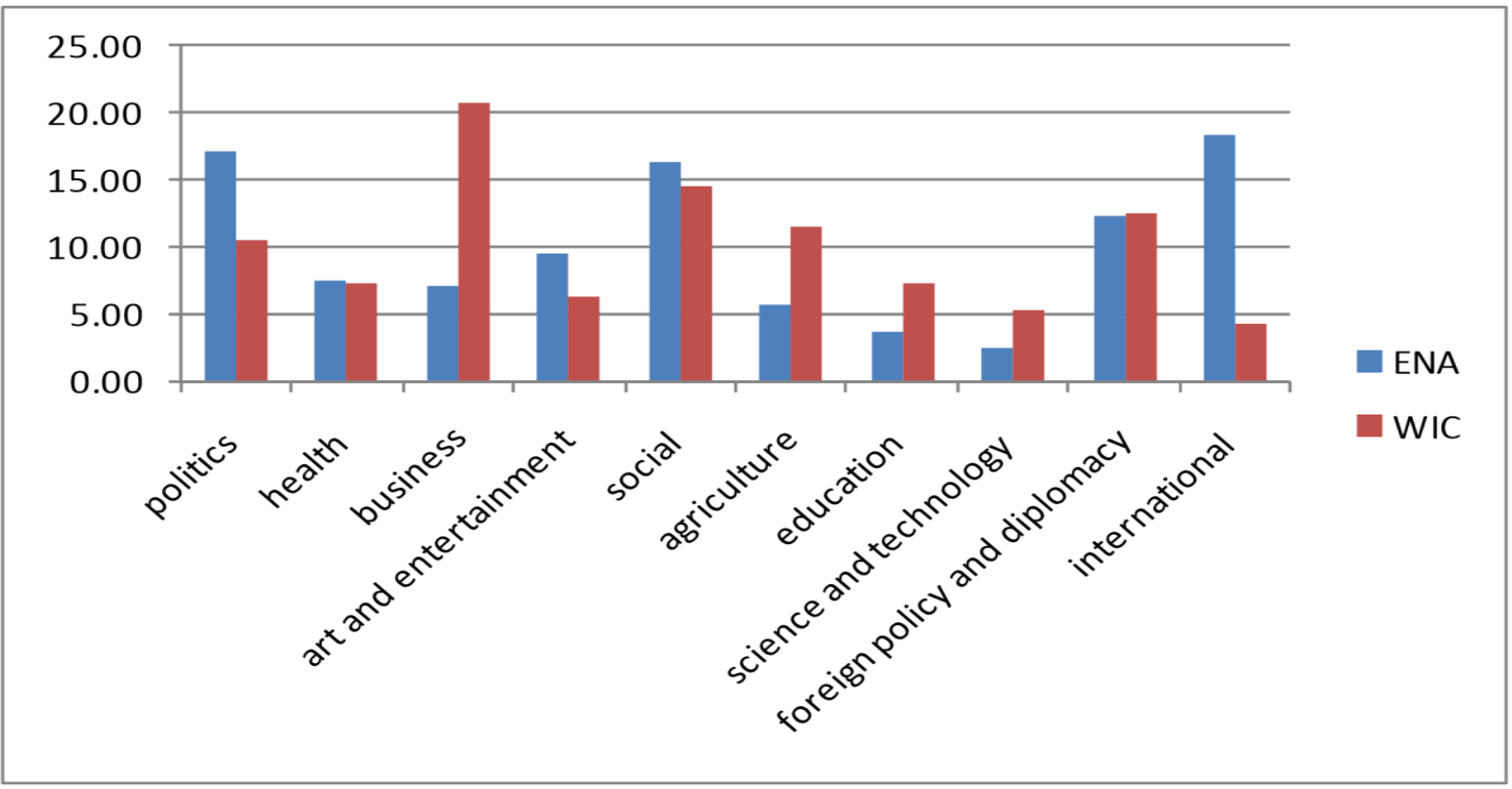

Figure 1: The percentage of topics covered by the news media

From the figures, the researcher can comprehend that educational, health, and science and technology are topics that have got very little news recognition and attention by the news media. Very little has been said about topics of international issues in WIC news coverage, whereas ENA has given greater attention to them. Likewise, ENA has said too little on topics of business while WIC gives the highest attention for same issues. Despite the fact that topics of news and focus of attention given for them are varied, the researcher can conclude that the range of their news coverage is diverse and wide, and the proportion of their news coverage is imbalance.

\section{News Sources}

Knowing and identifying the nature and the type of news sources can indicate something about sources that have been used to make news as well as the degree of journalists' engagement in reporting and disseminating research findings. It is known that wire services have three news sources. These are: sources - originated materials, such as; speeches,press releases, meetings, seminars, journals, conferences, research reports; reporters; and foreign news agencies. As a result, news source are coded accordingly and the percentage of usage of sources are analyzed based on these three types of sources. The following chart (see Figure 2) has shown majority of the news are reproduced from source-originated materials than from reporters' own observation and foreign news 
agencies. From the figures, it is also easy to understand that the engagement of reporters in the public affairs and in the work of news reporting or production of news is too fragile in both media. They are highly confined those news stories that have come up as the news tips. ENA has used foreign news agencies as source of news in a great deal than WIC. Even if the media used foreign news agencies, the figures have, further, indicated that they provide better attention and coverage for domestic issues than foreign issues.

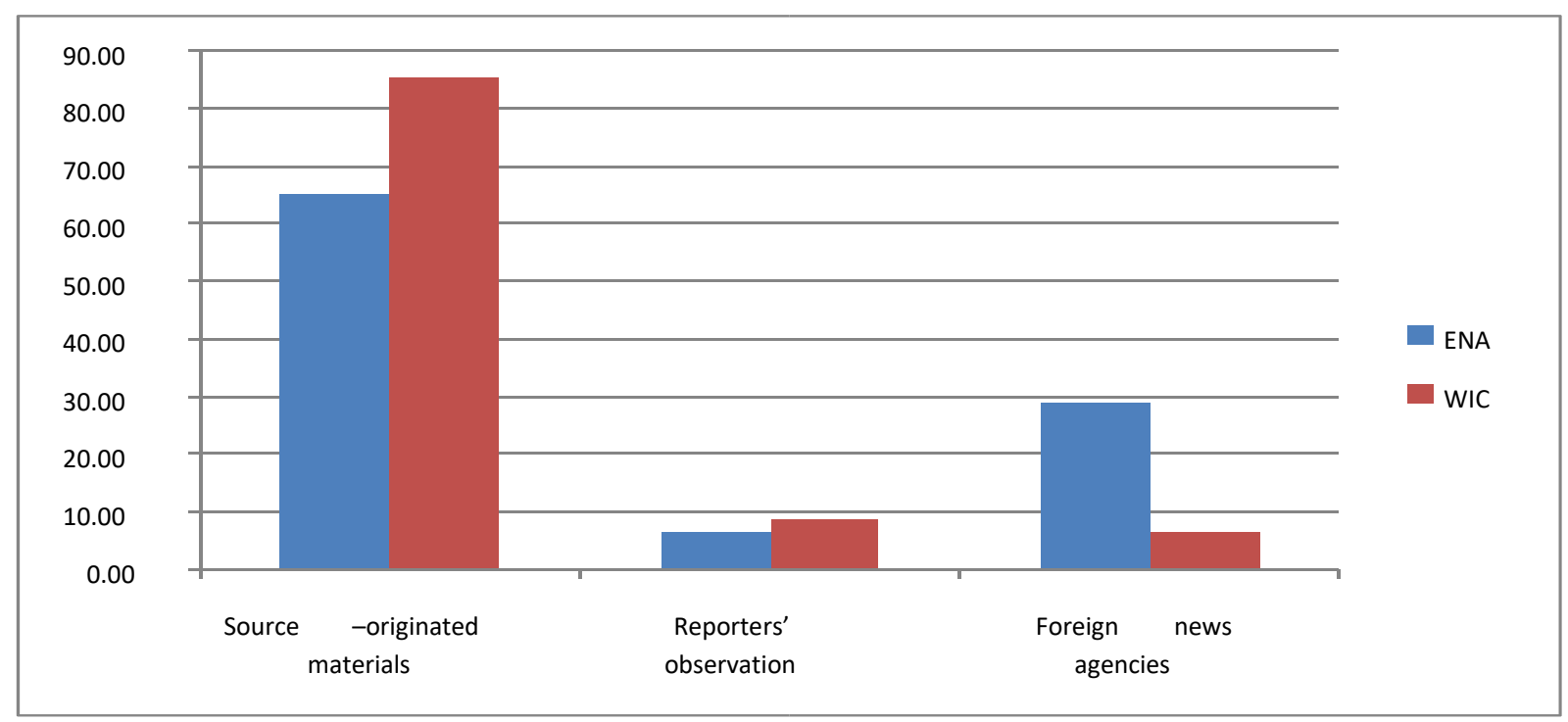

Figure 2: Types of news source in percent

From the figures shown in the chart (see Figure 3), it can be understood that a large amount of political and social issues $(21.02 \%)$ have been reproduced from source - originated materials followed by issues of foreign policy and diplomacy (12.74 \%) and business (10.83\%) than other issues in the news coverage of ENA. In the case of WIC news coverage, much of business issues (21.95\%) have been reproduced from source - originated materials followed by social issues and issues of foreign policy and diplomacy $(14.63 \%)$ than others. These figures have also indicated that both news media are much dependent on news tips which have been provided by news makers. News makers can be individuals or organizations. Moreover, the researcher can take for granted that journalists can be influenced by those who provide the news tips from government organizations. 


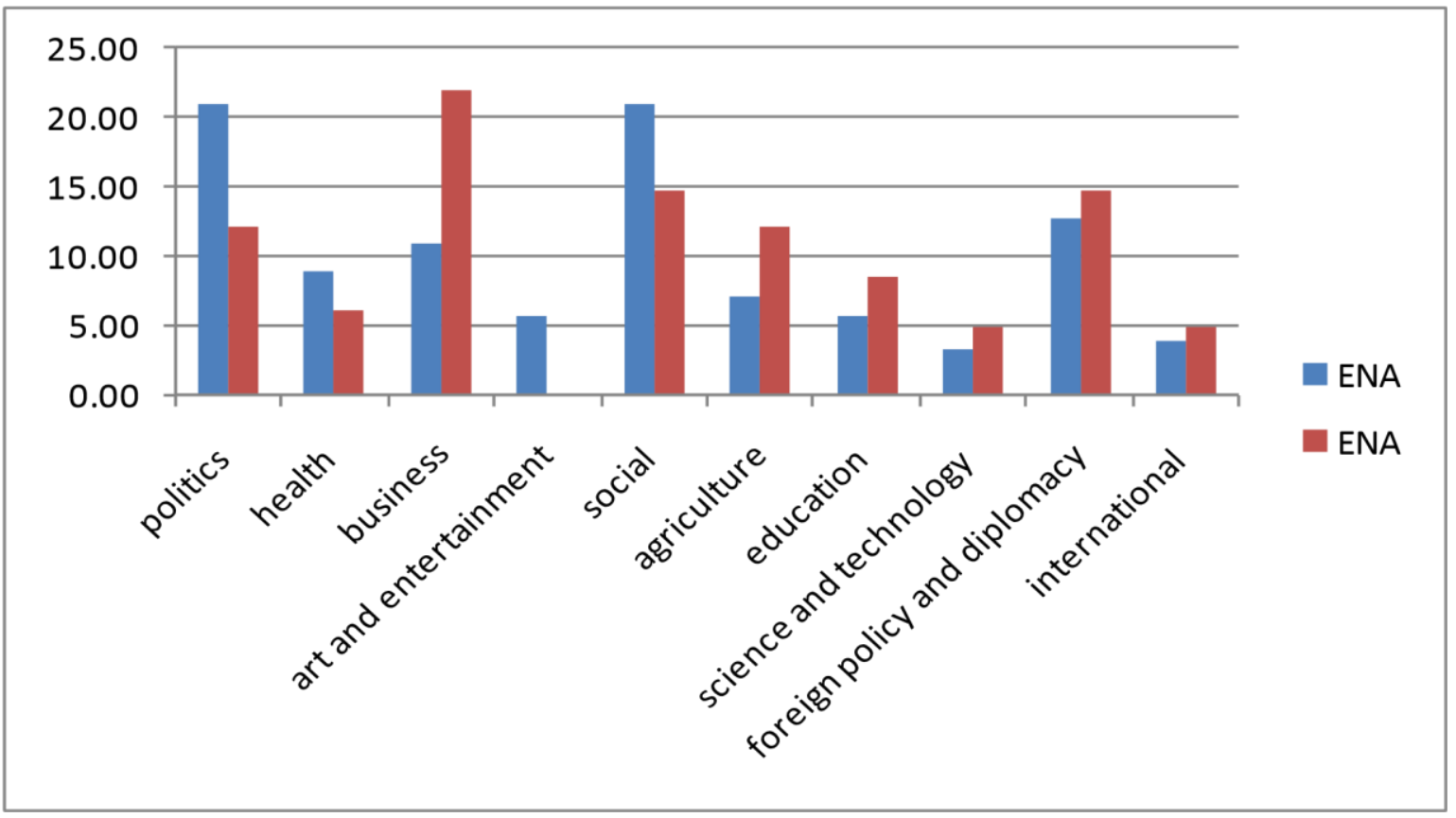

Figure 3: The percentage of topics of news basis on source- originated materials (speeches, press releases, meetings, seminars, journals, and research reports)

Figures in the chart (see Figure 4) have indicated that journalists, who are working in ENA, had better engagement in reporting art and entertainment (75\% coverage) followed by business affairs. In the case of WIC, in covering art and entertainment affairs (46.67\%), journalists' direct observation has been observed followed by issues of politics (26.67\%). Journalists have also little engagement in covering health and social issues. The involvement of reporters of both media on art and entertainment issues is high. This might be due to the issues are not much politically sensitive and easy to handle than others. The engagement of reporters of ENA in covering issues of politics and health is also good. This also might be from the nature of media as it is government owned; degree of accessing public official could be open for them. In both news media, journalists has no any direct participation to cover issues, such as; agriculture, education, science and technology and foreign policy and diplomacy. Even if journalists' engagement in few topics of issues are stated in the figures; they also realized that journalists are also very much dependents of news tips. The figures have also indicated that journalists' engagement in reporting research findings are very low. This inference has been drawn it is because the literature also supports that research findings have mainly categorized and treated under the topics of news as science and technology. 


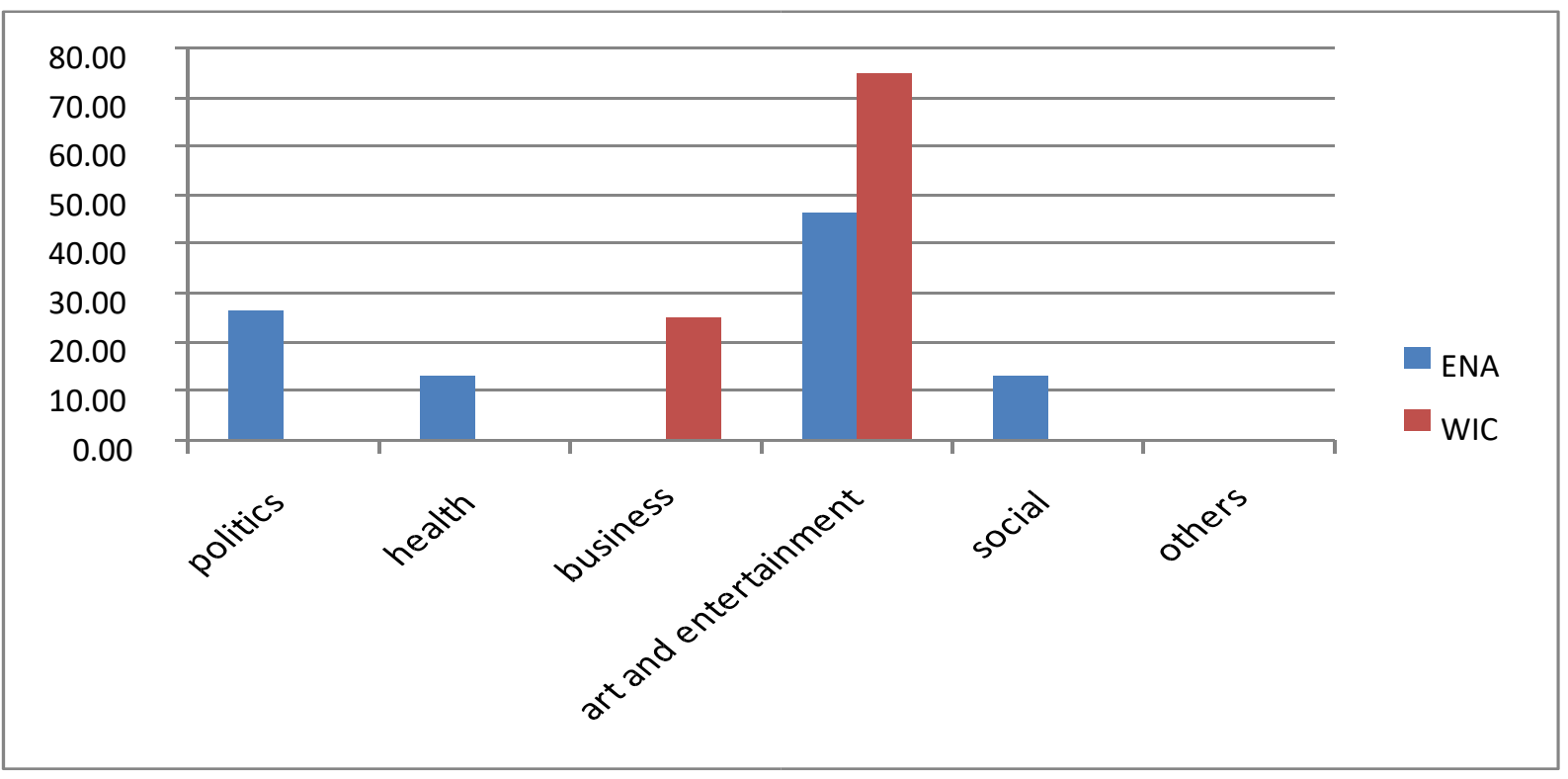

Figure 4: Reporters' Observation

The figures in the chart (see Figure 5) have shown that ENA has majorly used foreign news agencies when it covering international issues followed by art and entertainment and politics respectively. Unlike ENA, WIC has used foreign news agencies to cover health, social agriculture and science and technology. Form the figures, it is possibly understood that ENA has mainly concerned for local topics of news even if it gives better coverage for international affairs whereas WIC has used foreign news agencies to cover local issues. The researcher has understood that politics, health, art and entertainment, social, agriculture, science and technology, and foreign policy and diplomacy are topics which have taken foreign media coverage with varied amount of news coverage. 


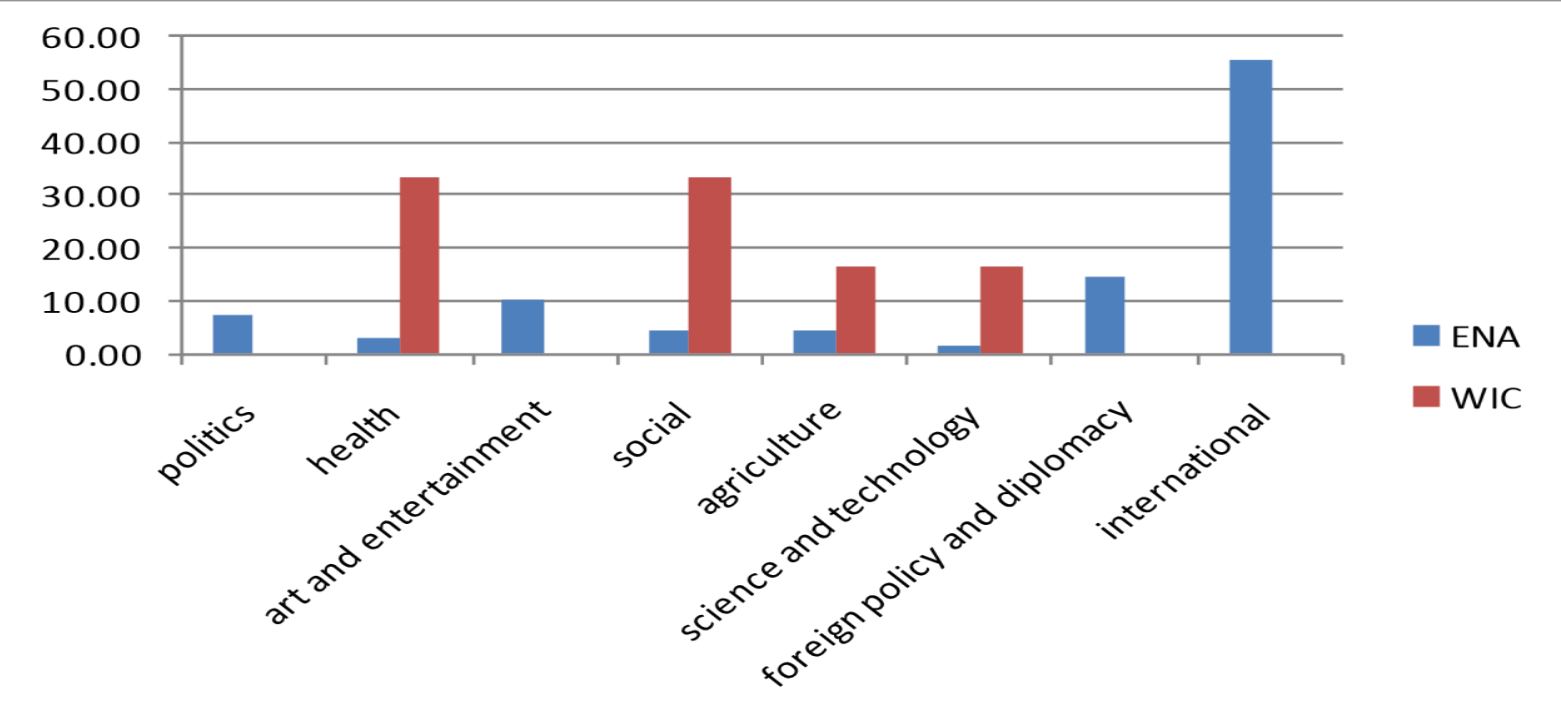

Figure 5: Foreign News Agencies

\section{News Coverage of Research Findings}

The figures in the chart (Figure 6) have shown that the total news coverage of research findings that are given by the news media in comparing with all others topics of the news, which are coded by the researcher, are very little. It is easy to observe that very little has said about research findings in their news coverage. Thus, the figures have further indicated that ENA and WIC have little engagement in disseminating research findings to the general public. Moreover, the figures have implied the contribution of ENA and WIC in disseminating research findings becomes too low. 


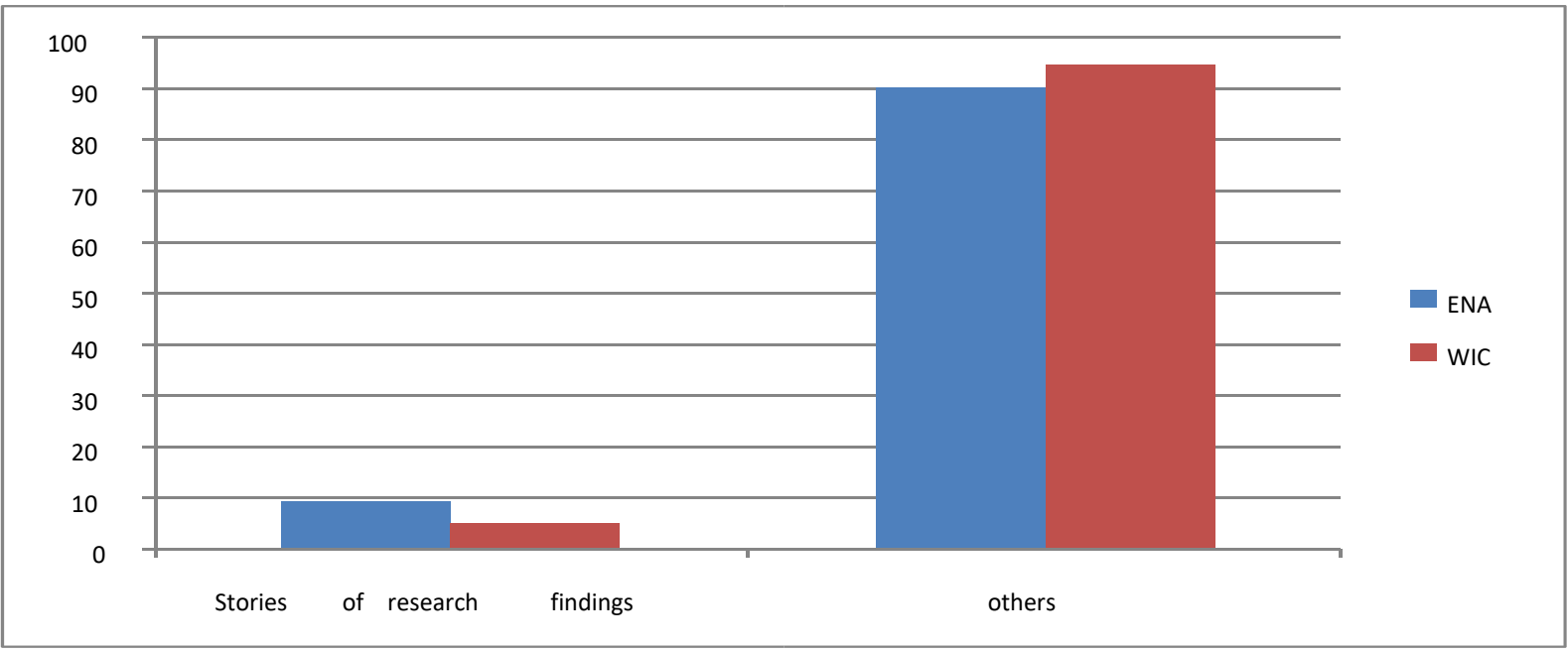

Figure 6: Total percentages of the coverage of research findings in the news

Figures in the chart (see Figure 7) have shown that there is better news coverage of health (ENA, 34.78\%; WIC, 40\%) and social research findings (ENA, 30.43\%; WIC, 40\%) out of the whole stories which talk about research results (see Figure 6), followed by agricultural research findings (ENA, 13.04\%; WIC, 20\%). ENA has said very little about educational, science and technology research findings as well as those international research findings whose themes are various while WIC news coverage on the same topics are nil. Thus, from these figures, it is possible to conclude that many research findings whose topics are diverse have been deliberately ignored by the news media or couldn't get news media coverage. 


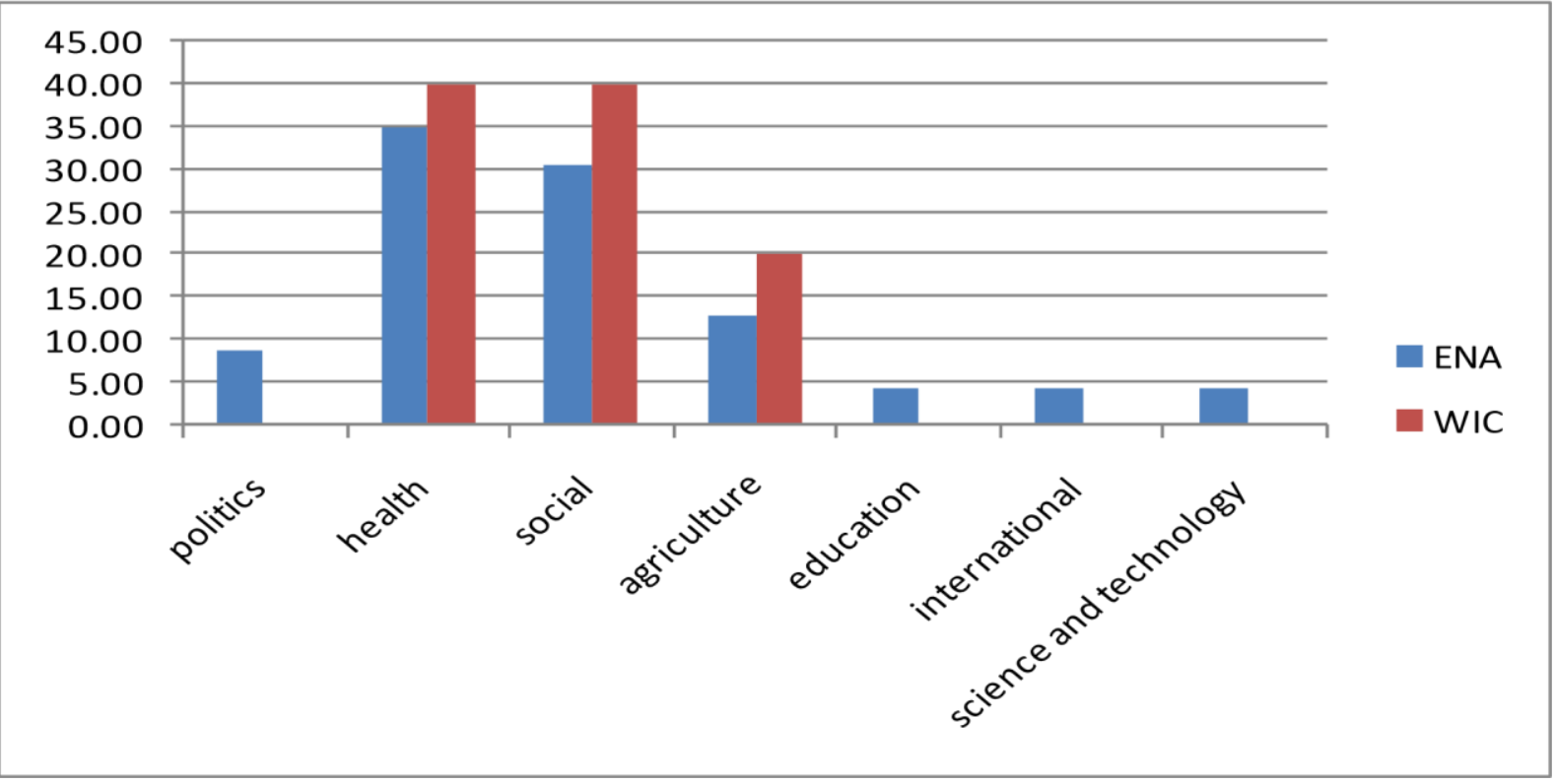

Figure 7: Percentage of research findings appeared in the news stories per issue

\section{Local or Foreign Research Findings Are Covered?}

The figures in the chart (Figure 8) have explicitly shown both wire services have said better about foreign research findings than domestic one. The figures implied that very little has said about domestic research findings in news media. However, it has been seen that the appearance of local and foreign research findings in ENA news coverage has no considerable disparity. In case of WIC, however, the coverage of foreign research findings has been four times greater than the local one. It gives much news coverage for foreign research results. 


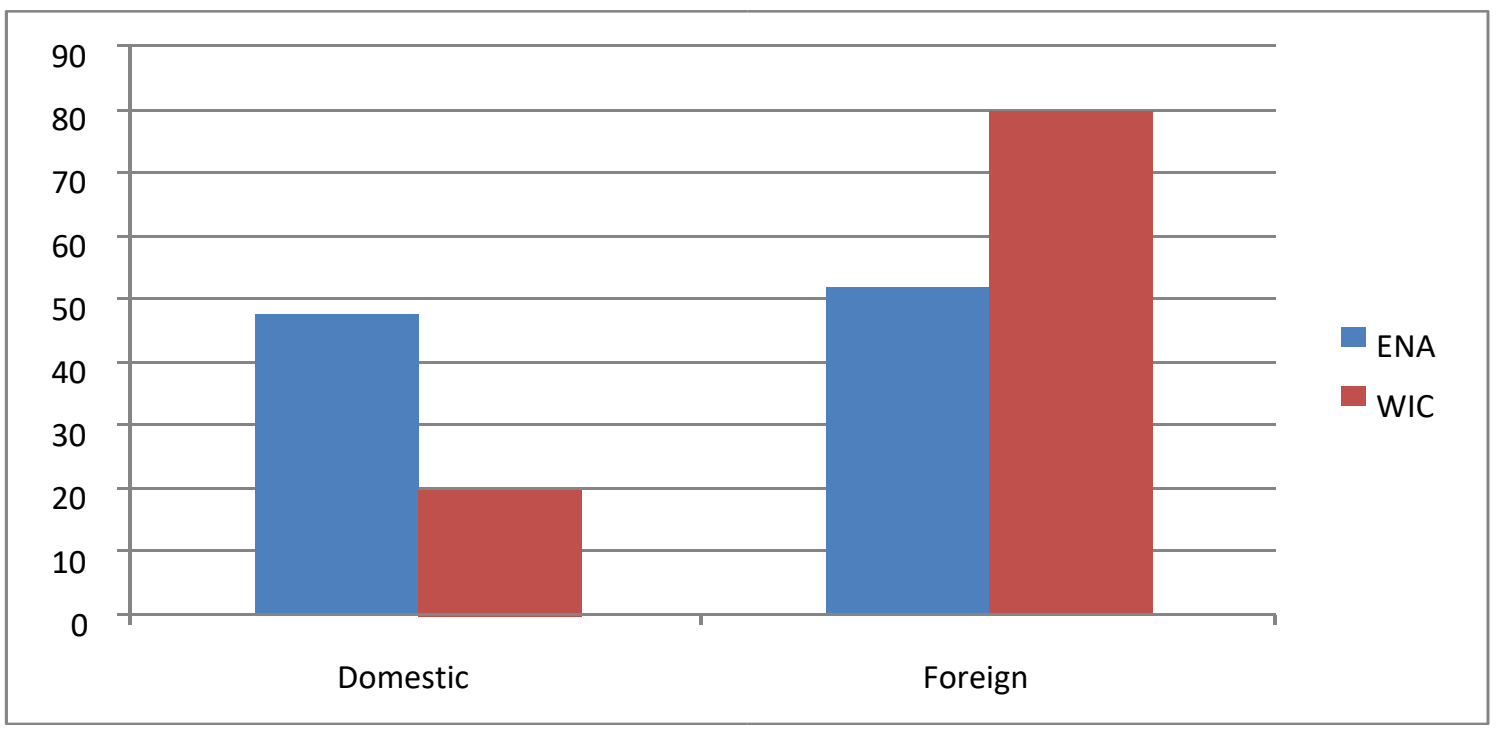

Figure 8: Geographic context of research findings in news coverage

The figures in the chart (Figure 9) have shown the total media coverage of domestic research findings. It can be understood that it is explicitly shown that both news media have insufficiently said about domestic research findings than any of other topics of the news. Therefore, it is simple to realize that domestic research findings have got little attention and recognition in the news coverage. The figures again conform that local news media have little participation in disseminating and popularizing research findings.

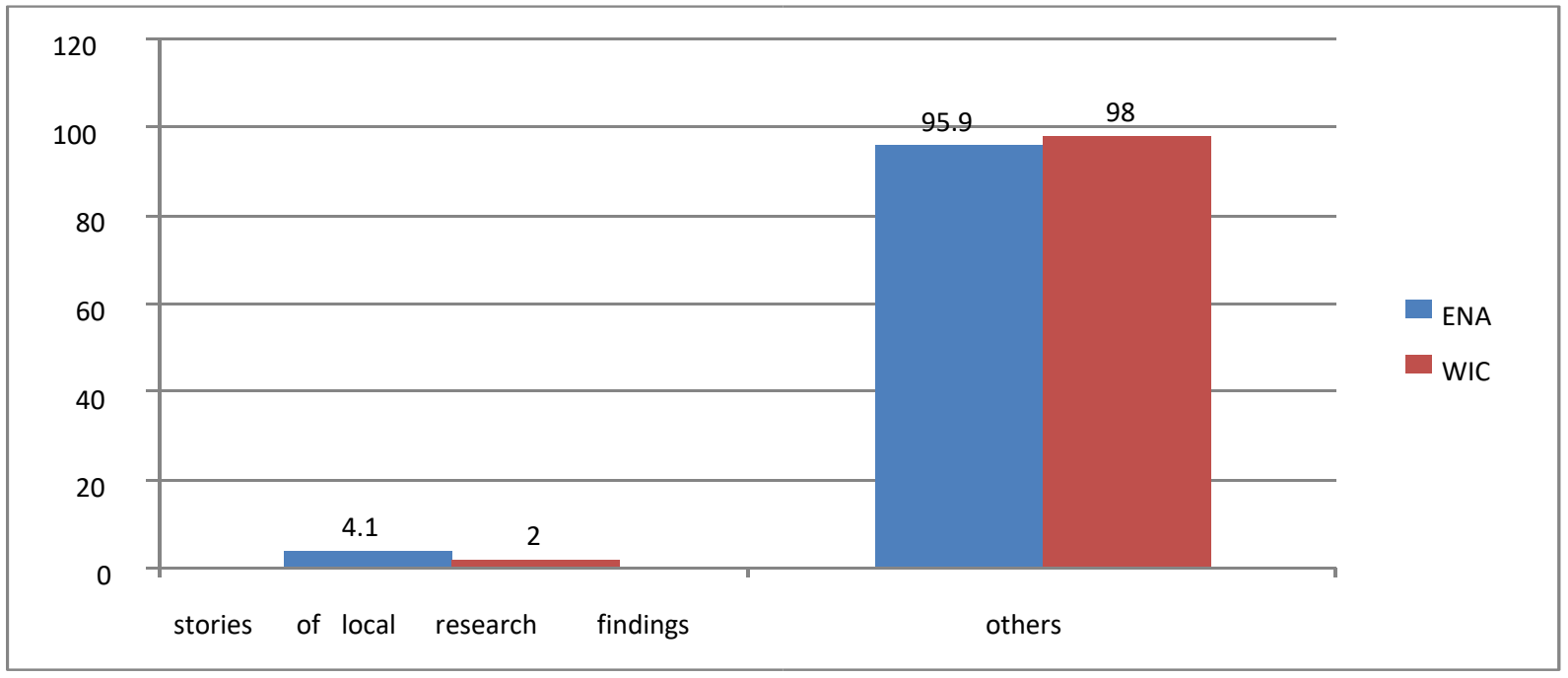

Figure 9: The total percentage of domestic research findings covered 


\section{Discussion}

In this section, findings that are drawn from media/journalists' responses are dealt with for the purpose of elucidation. Figures in the news coverage indicate issues of politics, business, art and entertainment, foreign policy and diplomacy and international has obtained priority in news coverage. Education, health and science and technology are also topics that have got little attention and appreciation in news coverage. From their response, the researcher understood that issues that are less politically sensitive and ease for journalists to handle have got better news coverage. The journalists' responses are also confirmed that agriculture, health, science and technology, innovations are issues they want to give priority and attention of the media. Figures in the news coverage are proven that the range of news coverage is diverse and wide, but the appearance of issues in news coverage are not proportional and balance. The responses of media are also proven that the selection and priority of the issues in the news are varied. They also responded that they are much concerned on developmental issues and public interests. In relation to research findings, figures in the news coverage have shown that mass media in this country have little said about local research findings. The journalists' responses are also confirmed that their news coverage of research findings are low and inadequate.

The journalists' responses are also show they are open for research and researchers; however, they overlook them, and they argued that this condition is oblivion in nature. Their response also indicated that they give research findings attention if the findings support development and solve practical problems. Figures in news coverage have also shown that the outcomes of local research are viewed helpful for the development of the country. It also implied that news selection is influenced by political ideology of the media. In general, in the research, it confirmed that local research findings are given least news coverage and recognition. Regarding to their news source, the figures in the news coverage have shown mainly news are not produced instead they are highly dependents on official and public relations news tips. The responses of journalists are also shown that journalists do not have considerable interest, engagement and commitment to produce news stories of research findings. They perceived that reporting research findings is viewed as difficult and mind-numbering task for journalist and seen as additional load for their job. 
The responses are also confirmed that there is no detail news structure or section that would take responsibility to cover local research findings. The responses indicate organizational structure as causative factor to overlook research findings in the news coverage. Thus, the engagement of news media, particularly journalists in research dissemination process is very low. In contrast, the media responses have also indicated that researchers do not view mass media as alternative research dissemination channels.

In relation to the role researchers' play in research dissemination, the media responses indicated that both researchers and journalists should understand that they have comparable roles in the media business; they have to be actors of media to improve scientific literacy and understanding. The media responses also indicates that the weakness of the media is originated from lack of detail planning for project news, and the media tradition and culture is often focused on making news which basis on official speeches. The responses also indicated that there is lack of skill in part of journalists to translate and make news from research findings; and misperception of journalists' concerning research dissemination as the duty of researchers rather than taking the responsibility themselves. These are weak sides of the media.

\section{Summary}

The aim of this research is to assess the news coverage of local research findings and to appraise the engagement of mass media in the process of local research dissemination. In order to achieve the objectives, the researchers designed mixed methodological research approaches; i.e., quantitative and qualitative. To draw the required data for the research, content analysis and indepth interview are used. Then, the following major findings are disclosed.

$>$ Educational, health, agricultural and science and technology are local topics that have got very little news recognition and attention by the news media.

$>$ The range of their news coverage is diverse and wide, but the proportion of issues appeared in the news coverage is imbalance.

$>$ The engagement of reporters in reporting public affair and in the work of news reporting or production of news is too fragile in both media. Their coverage are highly confined those news stories that have come up as the news tips. 
$>$ Journalists' engagement in reporting research findings are also very low. The contribution of ENA and WIC in disseminating research findings is low.

$>$ The coverage of local and foreign research findings of ENA is almost the same and equal in proportion. Whereas in the case of WIC, the coverage of foreign research findings is quadruple than the coverage of local research findings.

$>$ Domestic research findings have got little attention and recognition in the news coverage.

$>$ Journalists don't have considerable interest, engagement and commitment to cover research findings, even though they believed mass media are importance to research dissemination and transferring knowledge.

$>$ Even if they least said about research findings, the media responses indicates editorial policy of ENA and WIC is open for research and researchers. In relation to editorial policy, journalists' responses has also indicated the importance of articulation of the role of news media in research dissemination in their directives. However, there is no detail organizational structure that could liable for news coverage of research findings.

$>$ The weakness of ENA and WIC originates from their failure to include research issues in planning; journalists' attitude and skill towards research; medias' tradition and culture; for example, they usually attend research seminars, but they simply make the speech of officials as news stories instead of research findings; poor relationship between mass media and researchers; and mass media dependency on public relations officers of government organization.

$>$ The strength of ENA and WIC is shown as they have an optimistic interest to connect and work with researchers at individual level managers and journalists for research works.

$>$ Inaccessibility of researchers and their works for the media; media preference for daily occurrences; translating and making stories from research findings; media tradition and culture; and lack of trained journalists in science journalism are some of the challenges the media have are found in this research. Another determining cause to feasibility of media coverage is access of information.

$>$ It is implied that scientific literacy and understanding of the journalists could be very little.

$>$ It is also implied that the researchers have been less attracted by the media and do not view mass media as channels of research dissemination. 


\section{Conclusion}

In general, the findings have shown local research findings have been given least attention and recognition in the news coverage of ENA and WIC. The research also proves that there is a gap between researchers and mass media, or between mass media and those institution which have a need of research dissemination. It shows ENA and WIC has least contribution for research dissemination and appreciation of researchers of the country. The findings have shown that inaccessibility of research works, filtration and selection process of the media, the media culture and tradition and lack of trained science journalists are the main challenge of the media. It also important to indicate the relevance of further study on the interaction of researchers and mass media in order to obtain the response of researchers towards to the mass media. In the literature, from historical contexts, it can be understood that mass media and science/ researchers has begun relationship when they observe the inadequacy of scientific literacy in the public. Even though it required further research, the findings has implication for researchers and the media will have much work to improve scientific literacy and public understanding about the inherent importance of research.

Therefore, it has to be known that dissemination research through mass media is helpful for the scientific literacy and understanding of the general public. Otherwise, without scientific literacy and public understanding, investing huge capital for research would become fruitless.

\section{Recommendation}

Based on the findings of the research, the following recommendation has been forwarded for each concerned bodies.

- ENA and WIC should include and set specific arrangement in their organizational structures so that to make journalists liable and accountable for the coverage of local research findings.

- ENA and WIC in collaboration with other mass media of the country should arrange inhouse training about science journalism, particularly how to make news stories of research findings.

- Forum between scholars, researchers and journalists has to be arranged so that to improve the existing media tradition and culture.

- Science journalism should be included in the curriculum of journalism education in the country.

- Media directives or policies should set clear job description for journalists regarding to local research dissemination. 
- Researchers and scholars have to penetrate and collaborate with mass media to reach the end users of their research findings. They have to understand mass media as channels of research dissemination.

- Mass media including ENA and WIC has to work to enhance scientific literacy and understanding so that it is helpful for development of the country. Mass media including ENA and WIC should use researchers and scholars as expert sources of information as their key for improvement of their communication. 


\section{References}

Akala, J. W. (2004). Can journalism enhance dissemination of higher education? A critical analysis of Kenya's print media. Paris: UNESCO colloquium on Research and Higher Education Policy.

Bero, L. B., Boyd, E. A., Cook, D. M., \& Grossmann, C. (2009). Journalists and conflicts of interest in science: beliefs and practices. Accessed from: www.int-res.com

Baran, J. S, \& Davis, K. D. (2012). Mass Communication Theory: foundations, ferment, and future. $4^{\text {th }}$ ed. USA: Thomson Wadsworth.

Bauer, W.M, \& Bucchi, M. (2007). Journalism, Science and Society: science communication between news and public relations. Taylor and Francis Group, LLC. New York.

Burns, T. W., O'Connor, D. J. \& Stocklmayer, S. M. (2003) Science Communication: A Contemporary Definition. Public Understanding of Science. 12, 183-202. Accessed from http://pus.sagepub.com/content/12/2/183

Brewer, M. B. \& Crano, W. D. (2008). Principles and Methods of Social Research. London: Taylor \& Francis e-Library. (Adobe eReader Format) ISBN 1-4106-1313-5.

Brumfiel, G. (2009). Supplanting the Supplanting the old media? Nature, 458, 274-277.

Bryman, A. (1998). Quantity and Quality in Social Research. In M. Bulmer (Eds) Contemporary Social Research Series, 1-195.

Bryman, A. (2004). Quantity and Quality in Social Research. London: Taylor \& Francis eLibrary. (Adobe eReader Format) ISBN 0-203-71826-7.

Chan, L, \& Costa, S. (2005). Participation in the global knowledge commons: Challenges and opportunities for research dissemination in developing countries, 106(1210/1211), pp. 141163. Emerald Group Publishing Limited.

Committee on Science, Engineering, and Public policy. (2009). On Being A Scientist: a guide to responsible conduct in research. National academy of sciences, national academy of engineering, and institute of medicine. Washington, DC: The national academy of press.

Dawson, C. (2009). Introduction to Research Methods: A practical guide for any undertaking a research project. $4^{\text {th }}$ ed. UK, How To Books Ltd. (Adobe eReader Format) ISBN 9781 848033429. 
Davies, S. R. (2008). Constructing communication: Talking to scientists About Talking to the Public. Science Communication, 29(4), pp.413-434. Accessed from: http://online.sagepub.com

Dunwoody, S. (2008). Science journalism. Bucchi, M. \& Trench, B. (Eds.) Handbook of public communication of science and technology, (pp. 15 -24).

Dunwoody, S. (2008). What's a Journalist to Do? Challenges and Approaches to Reporting Scientific Assessment. In J. Susan Hassol \& J. Katzenberger (Eds.), Characterizing and Communicating Scientific uncertainty: A Report of the Aspen Global Change Institute Elements of Change Series (pp. 46-49). Colorado, USA.

Einsiedel, E. F. (2008). Public participation and dialogue. In M. Bucchi \& B. Trench (Eds.) Handbook of public communication of science and technology, (pp.173 - 184).

Eperen, L. V., Marincola, F. M., \& Strohm, J. (2010). Bridging the Divide between Science and Journalism. Journal of Translational Medicine. Accessed from: http://www.translationalmedicine.com/content/8/1/25

European Commission. (2007). European Research in the Media: What do media professionals think? Research-eu. Accessed on 7/14/2010 from http://ec.europa.eu/research/research-eu

Fauman, J., \& Sharp, H. (1958). Presenting the Results of Research to the Public. Public Opinion Quarterly, 22, 107-115.

Fico, F., Lacy, S., \& Riffe, D. (2008). Analyzing Media Messages: Using Quantitative Content Analysis in Research. London: Taylor \& Francis e-Library. ISBN 1-4106-1342-9.

Jensen, K. B., \& Jankowski, W. N. (2002). A Handbook of Qualitative Methodologies for Mass Communication Research. London: Taylor \& Francis e-Library. (Adobe eReader Format) ISBN 0-203-71804-6.

Gunter, B. (2000). Media Research Methods: Measuring Audiences, Reactions and Impact. London: SAGE Publications Ltd.

Kiernan, V. (2003). Diffusion of News about Research. Science Communication, 25(1), 3-13, Sage Publications.

Krippendorff, K. (2004). Content Analysis: an introduction to its methodology. London, UK: Sage Publications, Inc. ISBN 0-7619-1544-3. 
Kothari, C. R. (2004). Research Methodology: Methods and Techniques. (2 ${ }^{\text {nd }}$ ed.). New Delhi, New Age International (P) Limited, Publishers. ISBN (13): 978-81-224-2488-1.

Lewenstein, B. V. (2002). Editorial: A decade of Public Understanding, 11, 1-4. Accessed from: http://pus.sagepub.com/content/11/1/1.refs.html

Lievrouw, L. A. (1990). Communication and the social representation of scientific knowledge. Critical studies in mass communication, 7(1), 1-10.

Miller, J. D. (2004). Public understanding of Science and attitudes toward scientific research: what we know and what we need to know. Public Understand. Sci. 13, 273-294. Sage Publications. Accessed from www.sagepublications.com .

McQuail, D. (2003). McQuail's Mass Communication Theory. ( $4^{\text {th }}$ ed). London: Sage Publications.

Media for science forum. (2010). Declaration Media for science forum. Available at www.mediaforscience.com Accessed on 7/27/2010.

Motomu, I., \& Suleski, J. (2010). Scientists are talking, but mostly to each other: a quantitative analysis of research represented in mass media. Accessed on October 24, 2010 from http://pus.sagepub.com/content/19/1/115

Rao, K. M. (2001). Scholarly Communication and Electronic Journals: issues and prospects for academic and research libraries. Library Review, 50, 169-175.

Schäfer, M. S. (2009). From Public Understanding to Public Engagement: An Empirical From Public Understanding to Public Engagement. Science Communication, 30(4), 475-505. Accessed from http://scx.sagepub.com/content/30/4/475.

Schudson, M. (2003). The Sociology of News: contemporary societies. USA: W.W. Norton \& Company, Inc.

Semir, D. V. (2000). Scientific journalism: Problems and perspectives. Internatl Microbiol, 3, 125 128, Springer-Verlag Ibérica, Spain.

Semir, D. V. (2010). Science Communication \& Science Journalism. Accessed from www.mediaforscience.com

Silcock, J. (n.d). Disseminating Research: Choosing How and Where to Publish. Accessed on 7/27/2010 from www.leedsuniversity.uk.edu

Skjerdal, T. S. (2012). Competing loyalties: Journalism culture in the Ethiopian state media (Doctoral thesis), University of Oslo. 
Sweden International Development Association. (2003). Ethiopia: Survey of Culture and Media. Stockholm.

Tenaw Terefe W/Mariam. (2006). Science Journalism in Ethiopia: Evolving a Viable Science

Communication Model for Scientific Awareness among the Public. Addis Ababa

University, Ethiopia.

Tumber, H. (1999). News: a reader. Oxford University press Inc. New York.

Thelwell, M. (2004). Research Dissemination and Invocation on the Web. Online Information Review, 26, 413-420.

Thompson, R. A., \& Nelson, C. A. (2001). Developmental Science and the Media: Early Brain Development, 56(1), 5-15.

UNESCO. (2014). Free, Independent and Pluralistic Media in the Post-2015 Development Agenda: A Discussion Brief.

Vincent, R. (2005). Communicating Health Research: How Should Evidence Affect Policy and Practice. Accessed at 7/26/2010 from www.healthlink.org. 